\title{
Transcranial Doppler-guided selective antegrade cerebral perfusion during aortic debranching operation
}

\author{
Ali Khoynezhad, MD, FACC, FACP, ${ }^{\mathrm{a}}$ and Rolando Celis, $\mathrm{MD}^{\mathrm{b}}$
}

We report the utility of transcranial Doppler (TCD) during hybrid repair of an aneurysmal enlargement of a proximal descending thoracic aortic dissection. TCD provided critical information for the need of selective antegrade cerebral perfusion (SACP) and adequacy of cerebral blood flow during the procedure.

\section{CLINICAL SUMMARY}

A 64-year-old man with acute type A aortic dissection had emergency aortic valve repair, annuloplasty of sinutubular junction, and hemiarch replacement. He recovered well from the original operation. However, on postoperative day 4 , a computed tomography scan obtained due to back pain revealed expansion of the false lumen of the aortic arch distal to the previous hemiarch graft. The patient did not wish a second operation with hypothermic circulatory arrest to replace the total arch, but agreed to undergo extra-anatomic bypass of the brachiocephalic vessels (aortic debranching) followed by endografting of the distal aortic arch and the proximal descending thoracic aorta.

In the operating room, access to the chest was gained through his previous median sternotomy. The main body (14 mm) of a trifurcated Vascutek graft (Renfrewshire, Scotland, UK) was anastomosed to the ascending aortic graft using a side-biting clamp. The $8-\mathrm{mm}$ branch of the trifurcated graft was anastomosed end-to-end to the left carotid artery. During this anastomosis, the mean velocities in the left middle cerebral artery (MCA) did not drop, revealing an adequate antegrade perfusion through collaterals. Subsequently, the innominate artery was briefly clamped in preparation for extra-anatomic bypass; however, immediately after this maneuver, the right MCA velocities dropped. SACP was deemed necessary to provide adequate cerebral perfusion, and the Hemashield (Boston Scientific Co., Natick, Mass) graft sutured to the right axillary artery during the previous operation and a right femoral venous line were used to establish normothermic SACP during extra-an-

\footnotetext{
From the Sections of Cardiothoracic Surgery ${ }^{\mathrm{a}}$ and General Surgery, ${ }^{\mathrm{b}}$ University of Nebraska Medical Center, Omaha, Neb.

Received for publication April 10, 2008; accepted for publication May 18, 2008; available ahead of print Sept 16, 2008.

Address for reprints: Rolando Celis, MD, University of Nebraska Medical Center, General Surgery, 982315 Nebraska Medical Center, Omaha NE 68198-2315 (E-mail: rcelis@unmc.edu).

J Thorac Cardiovasc Surg 2009;138:1029-30

$0022-5223 / \$ 36.00$

Copyright (c) 2009 by The American Association for Thoracic Surgery doi:10.1016/j.jtcvs.2008.05.051
}

atomic bypass of the 14-mm graft branch to the innominate artery. The heart perfused the rest of the body. SACP flow was initiated at $10 \mathrm{~mL} \mathrm{~kg}^{-1} \mathrm{~min}^{-1}(0.7 \mathrm{~L} / \mathrm{min})$; however, the TCD revealed a fall in the peak velocity over the right MCA from $36 \mathrm{~cm} / \mathrm{s}$ to $25 \mathrm{~cm} / \mathrm{s}$. Therefore, the SACP was incremented to $1.3 \mathrm{~L} / \mathrm{min}$, achieving a peak velocity of $36 \mathrm{~cm} /$ s. SACP was terminated after antegrade flow to innominate artery was reestablished (duration of SACP: 15 minutes). As access to the left subclavian artery was deemed problematic from the anterior mediastinal approach, the third graft branch $(8 \mathrm{~mm})$ was ligated.

For endovascular access, a 10-mm Dacron graft was anastomosed to the ascending aorta using a partial occluding

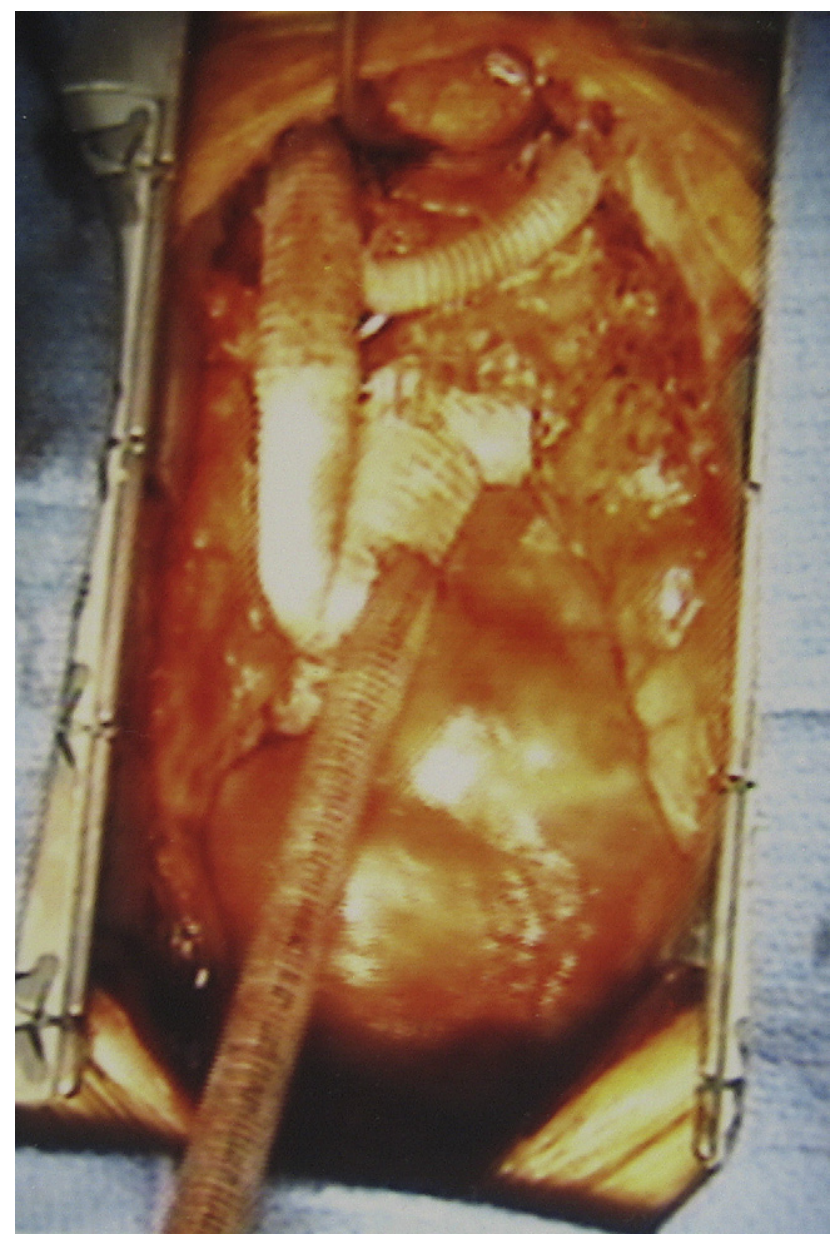

FIGURE 1. 3D reconstruction of an axial CT scan revealing the extraanatomic bypass to the innominate and left carotid artery, and patent left subclavian artery beyond the stent graft. 


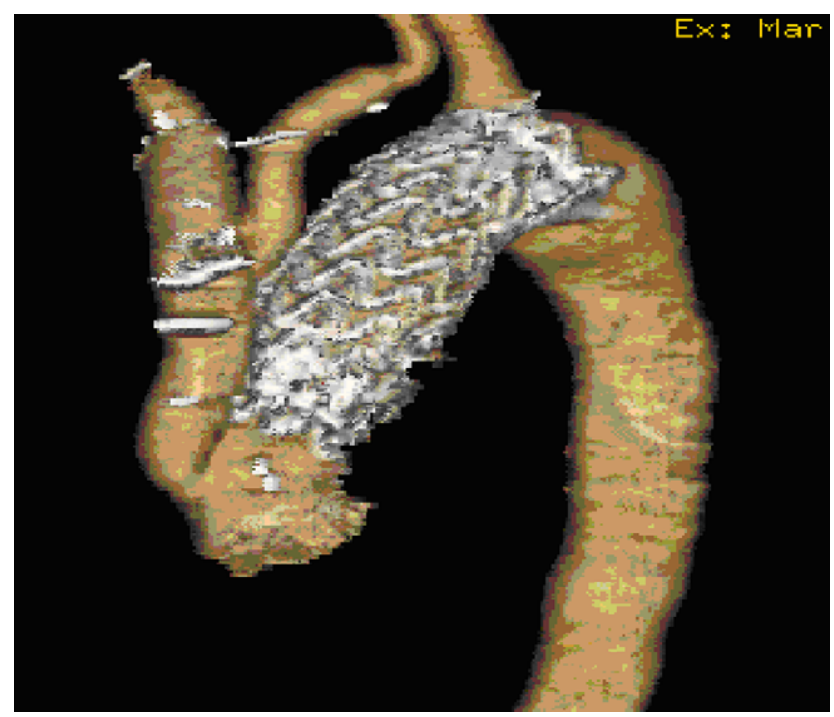

FIGURE 2. Intraoperative findings after antegrade deployment of the stent graft through the $10 \mathrm{~mm}$ Dacron graft anastomosed to the ascending aorta.

clamp. A $34 \times 10-\mathrm{mm}$ polytetrafluoroethylene stent graft was selected to achieve $11 \%$ oversizing compared with the previous $30-\mathrm{mm}$ Dacron graft in the ascending aorta. This was placed just distal to the junction of the radiographically marked Vascutek graft (Terumo Co., Inchinnan, Scotland) in antegrade fashion. Completion angiogram revealed exclusion of the entire aortic arch and proximal descending thoracic aorta, without evidence of endoleak (Figures 1 and 2).

The difference between left and right radial mean arterial pressures was $5 \mathrm{~mm} \mathrm{Hg}$, thus the intended left subclavian-carotid transposition was not performed. The patient did well after surgery and was discharged on postoperative day 2 .

\section{DISCUSSION}

Multiple neuroprotective strategies are used during aortic arch replacement; however, the rate of permanent and transient neurologic dysfunction is $10 \%$ in centers of excellence. ${ }^{1}$ Although SACP is clearly a superior neuro- protective technique, ${ }^{2}$ the optimal flow rate of SACP remains uncertain. Most surgeons use a flow of $10 \mathrm{~mL}$; $\mathrm{kg}^{-1} \mathrm{~min}^{-1}$, as this roughly equals normal cerebral blood flow during normothermia. This flow rate may be inadequate for patients who have bidirectional perfusion of axillary artery (using the graft) and too high for patients under anesthesia and at profound hypothermia.

To our best knowledge, this is the first report to utilize TCD not only to determine whether SACP is required for a patient with incomplete circle of Willis undergoing aortic debranching procedure but also to adjust the rate of cerebral blood flow. After clamping of the innominate artery and initiation of SACP at a standard flow rate of $10 \mathrm{~mL} / \mathrm{kg}$, the right flow velocities were still lower than "baseline" velocities on $\mathrm{TCD}$, prompting us to adjust the pump flow to $1.3 \mathrm{~L} / \mathrm{min}$ to match the velocity observed before clamping. The cerebral blood flow rate will vary among individuals and depends on body temperature, intracerebral vascular resistance, and extracerebral vascular stenosis. The described method allows adjusting the flow rate to physiologic/anatomic needs of each individual. ${ }^{3,4}$

TCD monitoring plays an important role in preventing and identifying causes of permanent or transient neurologic damage during complex aortic arch or aortic arch debranching operations. Given its noninvasiveness, ease of use, and the critical information provided in major aortic operations, TCD should be part of the neuroprotective armamentarium of cardiothoracic surgeons.

\section{References}

1. Di Eusanio M, Schepens MA, Morshuis WJ, et al. Brain protection using antegrade selective cerebral perfusion: a multicenter study. Ann Thorac Surg. 2003;76: 1181-9.

2. Harrington DK, Fragomeni F, Bonser RS. Cerebral perfusion. Ann Thorac Surg. 2007;83:S799-804

3. Yu Q, Sun L, Chang Q, Sun G, Liu J. Monitoring of antegrade selective cerebral perfusion for aortic arch surgery with transcranial Doppler ultrasonography and near-infrared spectroscopy. Chin Med J. 2001;114:257-61.

4. Karadeniz U, Erdemli O, Ozatik MA, et al. Assessment of cerebral blood flow with transcranial Doppler in right brachial artery perfusion patients. Ann Thorac Surg. 2005;79:139-46. 